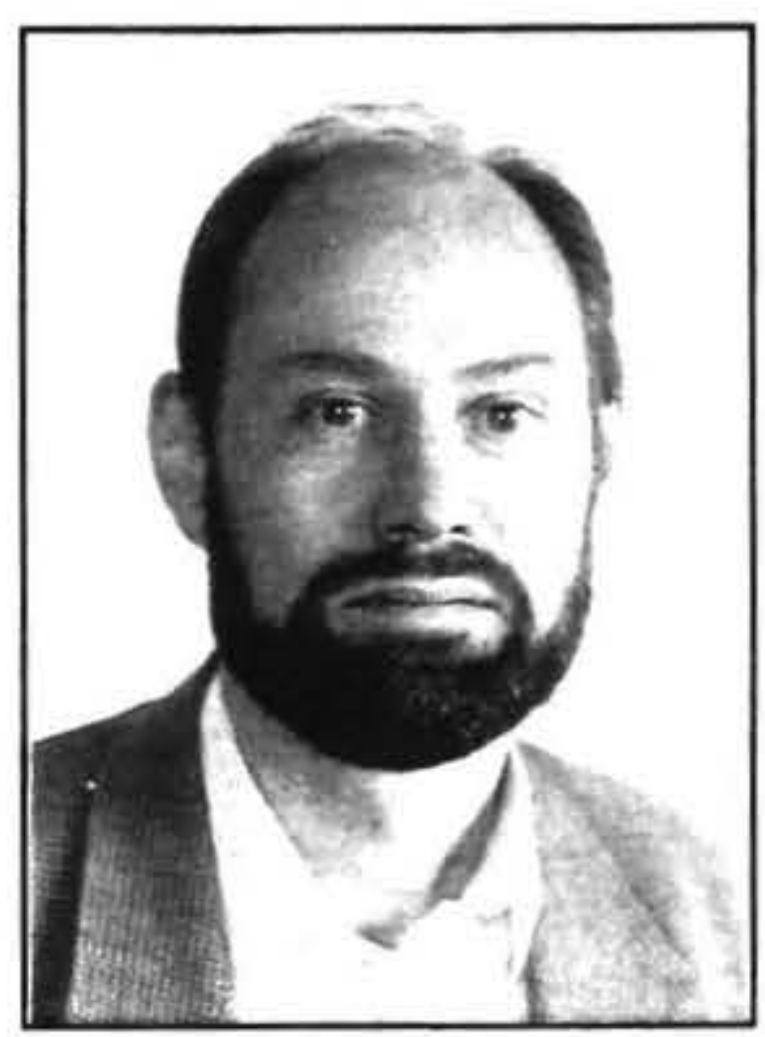

Department of Management and Employment
Relations, University of Auckland

\section{FLEXIBILITY AND CHOICE THROUGH LEAVE ENTITLEMENTS: IMPLICATIONS OF THE DANISH EXPERIENCE}

\author{
Erling Rasmussen
}

\begin{abstract}
Work pressure has increased for many people in New Zealand in the 1990s. Around a third of the workforce work more than 40 hours a week, the pressure to continuously upskill or reskill is growing, more women have joined the workforce, job and career insecurity has increased, and the eligibility age for receiving superannuation has risen. At the same time, 'underemployment' exist in terms of part-time workers wanting more hours and with unemployment stagnant at around six percent. Innovative Danish leave schemes introduced in the 1990s offer one way of addressing the problems of work pressure and under-employment simultaneously. The paper describes the leave schemes, the reaction of the workforce and outlines the associated social and economic costs and benefits. In particular, the analysis will focus on the trade-off between more employee flexibility, increased upskilling and improved family relationships on one hand, and, on the other hand, minimising both the fiscal implications and costs on individual employers. Finally, a possible application of similar leave schemes in New Zealand is discussed.
\end{abstract}

The New Zealand labour market has changed considerably in the last decade. Many of these changes are similar to changes in other OECD countries but widespread economic and social restructuring has exacerbated and accelerated the changes in New Zealand. In particular, the Employment Contracts Act has had a distinct impact on the types of flexibility pursued by employers (Rasmussen 1996a; Savage and Cooling 1996). Thus, the notions of segmented labour markets, dual labour market theory and atypical employment have often been used in describing recent labour market changes (eg Dixon 1995). There are clearly some gaps in our knowledge of the processes and outcomes in the secondary labour market (Whatman 1995) though it appears that cuts to penal rates and overtime payments have had a severe impact in the secondary labour market and that part-time employment and casualisation have become constraints on low-paid employees (eg. Brosnan \& Walsh 1996; Harbridge \& Street 1995). Furthermore, 'under-employment' has existed for some time with many part-time workers wanting more hours and with unemployment being persistently high in the 1990s. This has focussed the attention on the distribution of work.

The implications of part-time work and casualisation have been dealt with in two other research projects (Gleisner \& Rasmussen 1995; Rasmussen, Deeks \& Street 1996). Instead this paper will focus on the apparent increase in work pressure for many people in New Zealand in the 1990s. The 40-hour week has become less prevalent under the Employment Contracts Act. The workforce is roughly split into three sections where one-third (32.9 percent) usually work less than 40 hours per week, another one-third ( 31.7 percent) usually work the traditional 40-hour week and one-third (35.4 percent) work more than 40 hours per week (Statistics NZ 1996a). With the majority of people working more than 40 hours per week, this raises a number of questions about work distribution, balance between work and family life, and longer term health, productivity and decision-making implications. "Of those people who usually work more than 40 hours, a significant proportion usually work very long hours. About one in four people (147,000 or 26.4 percent) who usually worked more than 40 hours in 1994/95 usually worked at least 60 hours, with 60,300 (10.8 percent) usually working at least 70 hours" (Statistics New Zealand 1996a: 177).

It is important to stress that there are no explicit restrictions on working hours in the Employment Contracts Act. In other $\mathrm{OECD}$ countries, there are two general forms of restrictions on working time: either a maximum limit on daily or weekly working hours or a statutory break/non-working period between two periods of work. In many OECD countries, collective arrangements may add further restrictions through limits on working time or through the 'disincentives' of penal rates or overtime payments. Under the Employment Contracts Act, reductions in penal, overtime and shiftwork rates/allowances have diminished the incentive for employers to limit long working hours (Contract vol $7 \& 15$; Harbridge \& Honeybone 1996; Armitage \& Dunbar 1993).

Besides many people working longer hours, work pressure has increased as part of the trend towards dual income families and the pressure to continuously upskill or reskill. The latter is associated with the quest for 'employability' as 
job and career insecurities mount. It has also become a more common notion that upskilling is the concern of the individual rather than the employer or the public. A particular New Zealand feature is the increase in the age of eligibility for receiving national superannuation in the 1990s. This will 'encourage' some people to stay working. This makes the ability to sustain one's working ability more crucial and breaks during the working life may be beneficial.

The increased work pressure can be detected through the popularity of terms such as family-friendly workplaces and balancing work and family responsibilities. Research is growing in these areas (eg Callister 1995; Podmore 1995). Generally, these attempts to increase flexibility for employees must be praised. It is problematic, however, that these initiatives may just facilitate an adjustment of working life in order to make people (read women) take up paid work more easily. Additionally, it appears to be a very reluctant and half-hearted approach so far. A study of family-friendly workplaces ("Work and Family Directions") by the Department of Women's Affairs found that employers tended to focus on cost implications rather than positive benefits and that most family-friendly initiatives were amongst the lower cost options available (Rasmussen 1996b: 113). In terms of allowing people to choose to take more time off work for family reasons, the election promises of the Labour Party and the Alliance of introducing paid parental leave may make more sense.

These are complex issues and obviously call for a multifaceted approach in order to sustain flexibility and choice in choosing between work and leisure. Innovative Danish leave schemes introduced in the 1990s offer one way of addressing the problems of work pressure and under-employment simultaneously. The paper will describe the Danish leave schemes and what prompted their introduction. It will discuss the reaction of the workforce and it will consider briefly the social and economic costs and benefits associated with such schemes. ${ }^{1}$ In particular, the analysis will focus on the trade-off between more employee flexibility, increased upskilling and improved family relationships on one hand, and, on the other hand, how to minimise both the fiscal implications and the costs on individual employers. Finally, a possible application of similar leave schemes in New Zealand is discussed.

\section{Leave schemes: why were they introduced?}

This paper will discuss the three temporary - now permanent - leave schemes that the Danish Government introduced in 1994. An overview of these leave schemes can be found in Table 1 (over). Before discussing the leave schemes, it is important to stress that the labour market context in which the temporary leave schemes are embedded is very different. Denmark, like New Zealand, has a number of traditional leave schemes in areas such a parental leave, sick leave, annual leave and leave for family reasons (Incomes Data Services 1991). The main difference is that these schemes are more generous both in time and in entitled allowances than the equivalent New Zealand schemes. These schemes are often extended through collective agreements which influence most of the Danish workforce. The Danish unemployment benefit and social welfare benefit systems are also renown for their high level of income support. Finally, the development of the key economic indicators ${ }^{2}$ and in particular the underlying economic policy approach are distinctly different from the New Zealand trends over the last decade, as detailed below.

Following the introduction of fiscal tightening and tax reform in 1986 and 1987, the Danish economy plunged into a low growth period with rising unemployment. However, the economic performance improved somewhat in the early 1990 s and this provided more 'economic space' to deal with the protracted problem of unemployment. The improved economic performance involved firstly, a dramatic shift from 25 years of balance of payments deficits to a large, sustainable surplus from 1989 and onwards. Secondly, the Danish economy entered a period of low inflation. Nevertheless, economic growth improved only slightly and unemployment continued to rise in the 1990-1993 period (OECD 1994).

These economic trends made unemployment the key economic problem. A number of influential economic commentators started to suggest that it could be a viable policy change to increase the budget deficit. It also became a common theme in the public debate that higher economic growth would not by itself be enough to solve the unemployment problem. Some people even rejected the possibility of obtaining full employment ever (eg Schjødt 1993). Thus, the status of unemployment as the main public policy issue was tinged with a fair dose of pessimism when evaluating the ability of traditional measures to combat unemployment.

At the same time, the issues of unemployment and employment were analysed by a number of public reports : the report from the Social Welfare Commission ('Socialkommissionen'), the public inquiry into labour market policy ('Zeuthen-udvalget'), several of the biannual reports of the Economic Council, reports from the Ministry of Finance in connection with the annual Budgets, and various OECD reports. The reports came with a number of different recommendations as they were often strongly coloured by the ideological disposition of the key authors. However, it would be fair to say that very few new ideas were presented though a few common themes emerged. It was a common theme that no significant decline in unemployment could be predicted for the foreseeable future. There were also a number of frequently used concepts such as activation, flexibility and education. While these concepts should be familiar to readers of OECD reports they often implied a whole raft of disparate measures because of the underlying philosophical differences flavouring the various reports. In particular, a general tension was running between recommendations that favoured a 'pull strategy' as opposed to a 'push strategy' in fighting unemployment. The former recommended creating 'space' - jobs - in the labour market for the unemployed while the latter would 'encourage' the unemployed to seek work by cutting benefits or by improving their skill levels. Both strategies started to emphasise individual counselling and action plans. Thus, the reports 
illustrated clearly that unemployment was a multi-faceted problem which called for a combination of approaches but there was no fundamental consensus regarding the balance and strength of these approaches.

While the 'economic space' improved in the early 1990s, it was a shift in the political arena that prompted a major change in the approach to decrease unemployment. Following the resignation of the Conservative-Liberal Government, a center-left coalition government dominated by the Social Democratic Party came into exists in January 1993. This Government introduced a change in the macro-economic policy towards a more expansive fiscal policy and it promised wide-ranging labour market reforms. The leave schemes were introduced as a part of these labour market reforms. While the change in government was crucial for the introduction of leave schemes, the previous government had already shifted towards a more pro-active approach to unemployment. For example, the so-called 'Activation Package' was agreed with the Opposition in 1992 and more resources were allocated to unemployment measures in the 1991 and 1992 Budgets. Additionally, the reports mentioned above had provided a number of ideas and plans upon which the incoming government could draw.

\section{The three temporary leave schemes - an over- view.}

As can be seen from Table 1, three types of leave schemes were introduced - education, child care and sabbatical leave. The education leave allowed a person to temporarily leave their job for up to 12 months to undertake study. The child care leave was on top of the standard parental leave entitle- ment (maximum of 28 weeks). Child care leave entitled to 6 months leave with an option for a further 6 months. the sabbatical leave was simply an opportunity for people to take a break from their job. While the intention for all the three schemes was that the vacant positions would be filled with unemployed people, only the sabbatical leave scheme has this a mandatory requirement. The schemes are open to the employed, the unemployed and the self-employed as long as these people are covered by one of the Danish unemployment insurance schemes. Education and sabbatical leave are limited to person over the age of 25 years and these people also need to have been in employment for at least 3 years. The child care leave option did not have these restrictions.

Table 1 indicates some of the key features of the leave schemes. An important feature is that there is a trade-off between the leave options and income. While the Danish unemployment benefit is generous by international standards it will often entail a substantial drop in income when the leave option is exercised. The reduction in income will generally be more substantial for highly paid people as even the maximum compensation through the unemployment benefit will be much less than their normal income. While the progressive income taxation will dampen the effect of such an income drop it will often involve a significant adjustment of personal finances to take up the leave option. Compensation was lower for sabbatical leave as the Government was more interested in promoting education and child care leave.

The second interesting feature is the differing abilities to exercise the leave option. The child care leave is an employee right since the employer cannot veto the leave option.

\section{Table 1: Temporary Leave Schemes}

\section{Leave Schemes: Rights \& Access}

Education leave

Child care leave

Sabbatical leave

Compensation

$100 \%$ of $U-E^{*}$ benefit

$80 \%$ of U-E* benefit

$70 \%$ of $U-E^{*}$ benefit

Period

12 months

6 months \& ability to

12 months

renegotiate another 6 months

Access

All U-E insured** that:
-can claim a
U-E benefit
-is 25 years or
older
-has been employed for 3
years

All U-E insured** that:

- can claim U-E benefit for

sickness \& child birth

- has been employed for 3

years

years

Return conditions As agreed

A right. As agreed if extended beyond 6 months

\author{
All U-E insured** that: \\ - can claim a U-E benefit \\ - is 25 years or older
}

Same job?

No

No

No

As agreed

* U-E $=$ unemployment

** covers employed, unemployed, self-employed

Source: Politiken Weekly, 28-4-1993, p. 17; Heising 1996. 
The access criteria are also less stringent than for the two other schemes, as detailed in table 1 . This is rather surprising since one would expect that the government would promote education leave - ie. make it a right and have less stringent criteria - as part of its general policy to upgrade the skill base of the workforce. The Government initially had a special incentive for the education leave which would attract a full 100 percent unemployment benefit in the period from January 1994 to April 1995 (Politiken Weekly 3-11-93).

Thirdly, the leave schemes are applied in a 'flexible' and decentralised manner. Besides the first six months of the child care scheme, the conditions on which the employee return to work have to be negotiated with the employer before the leave is taken. It implies that a return to the same job is not guaranteed. This is clearly another downside apart from the likely income reduction - to be taken into account in the employee's decision-making.

Fourthly, the schemes were presented as a temporary measure (as opposed to other leave arrangements). It was stressed from the outset that the schemes would be constantly monitored and, if necessary, the schemes could be adjusted if negative implementation or fiscal issues arose.

\section{The leave schemes: trends}

As discussed above, the leave schemes were only one element in a comprehensive strategy to limit unemployment. In its original presentation of the schemes in April 1993, the Government expected that around 20,000 (fulltime equivalent) persons would be involved in the leave schemes in 1994. It was expected that many people would only take 6 or 9 months leave and more than 20,000 people would therefore participate in the schemes.

It became clear in early 1994 that the Government had grossly underestimated the attraction of the leave options. A survey in October 1993 indicated that around 240,000 people were considering the option of taking leave in 19941995. Another survey found in late 1993 that most people - over 75 percent of the workforce - knew about the possibilities offered by the leave schemes (Kongshoj Madsen 1996: 10). At the same time, a number of different models to limit unemployment within particular occupations or organisations were discussed (Gleisner \& Rasmussen 1995). These models were based on the establishment of work groups of four to eight people. Within these work groups, people would take leave one week of every month or every second month. An unemployed person would then be employed full-time within these work groups. People had obviously considered these options carefully before they came into effect on 1 January 1994.

Every week, around 3,000 people started in the leave schemes in the first couple of months in 1994 . Over 46,000 people had entered the leave schemes after the first four months and this had grown to over 71,000 by August 1994. As detailed in table 2 , a total of 78,754 people participated in the schemes in 1994 and 69,335 in 1995 . This was way beyond the projections prior to the schemes and the substantial takeup of the leave opportunities was frequently reported in the media. While the majority of people opted for the child care leave in 1994, the education leave became more popular especially amongst unemployed people - 1995. Sabbatical leave is of minor importance as the number of people seeking sabbatical leave has declined sharply after the first rush of applicants in 1993 and early 1994.

The popularity of the schemes clearly surprised the Government. It was continuously pressured by the Opposition to 'do something' about the leave schemes during 1994-96. The Government reacted by making the schemes less generous. The maximum support of 80 percent of the unemployment benefit for the child care leave was cut to 70 percent in 1996 and will be further cut to 60 percent in April 1997. Additionally, fewer regional councils provided additional income support for people on child care leave (Aktuelt 9-596: 3). ${ }^{3}$ It also became less advantageous for unemployed to use the child care leave scheme. The sabbatical leave entitlement was limited to 60 percent of the unemployment benefit.

However, the Government remained firm in its support of the schemes. It announced in May 1996 that the leave options would become a permanent fixture of labour market policy. This led to a public clash between the Government and the three chair persons of the influential Economic Council ('the three wise men'). The debate illustrated two differing views of the Danish labour market and its functioning. "The Government thinks that the adjustments of the labour market policies have been sufficient. There are not

Table 2. Temporary leave schemes: number of people taking leave

\begin{tabular}{lrrrr}
\hline & Education & Child care & Sabbatical & Total \\
\hline Worker '94 & 6,837 & 22,359 & 5,876 & 35,072 \\
Worker '95 & 8,388 & 15,678 & 2,591 & 26,657 \\
Unemp. '94 & 16,143 & 26,084 & 0 & 42,227 \\
Unemp. '95 & 25,202 & 16,549 & 0 & 41,751 \\
Selfe. '94 & 185 & 1,270 & 0 & 1,455 \\
Selfe. '95 & 98 & 829 & 0 & 927 \\
Total '94 & 23,165 & 49,713 & 5,876 & 78,754 \\
Total '95 & 33,688 & 33,056 & 2,591 & 69,335 \\
\hline
\end{tabular}

Source: Arbejdsmarkedsstyrelsen (customised statistical information), April 1996. 
going to be further cuts to the leave schemes. No more adjustments to the early retirement option. However, the three wise men think that the growth in transfer payments make it necessary to implement further restrictions in order to counter the withdrawal of labour from the labour market." (Morgenposten Fyens Stifttidende 24-5-1996: 5).

\section{Leave schemes: issues}

This section will discuss the following issues: the economic justification of the schemes, the conversion rate (how many unemployed were offered jobs as a result of the schemes), the gender bias, income situation (are the schemes mainly for the well-off?).

It is clear from Table 2 above, that the leave schemes have enjoyed widespread public support. However, many experts and politicians have been partly or totally against these schemes. The main arguments against have stressed the fiscal costs involved and the negative impact on labour supply. In particular, the child care and the sabbatical leave schemes have been criticised for their lack of educational content. For example, the OECD pointed to the fiscal costs being unsustainable and the leave schemes creating skills shortages in the health sector (OECD 1994: 45-46). Danish employers have been highly critical of the schemes. Table 3 below indicates why this has been the case. Employers have fewer benefits from the schemes than employees and these benefits would seldom accrue in the short term. However, the employer is immediately faced with the practical problems associated with a permanent employee no longer being at work.

While the concerns about fiscal costs and restrictions on labour supply are valid proponents of the schemes have argued that the economic evaluations are based on a rather traditional economic reasoning. They take a narrow approach to measuring economic activity and could probably have given more value to the impacts of increased social and cultural mobility, improved family situations, the increased qualification levels and the decline in unemployment.

While the leave schemes were introduced to reduce unemployment there was an on-going debate as to how much the schemes would actually influence unemployment. The decentralised arrangements for adjusting the work flow effects of somebody taking leave implies that the average effect would depend on the tightness of staffing within the individual organisation and management's willingness to appoint a new employee in the leave period. A factor influencing the overall conversion rate was that the sabbatical leave option was associated with a 100 percent conversion rate since the employee had to secure an unemployed person for the job position before the sabbatical leave could be granted (Heising 1996: 207). It can be seen from table 2 that relatively few people exercised the sabbatical leave option. Overall, the Danish Labour Marked Board ('Arbejdsmarkedsstyrelsen') estimated from 1994 evidence that the schemes had a 57 percent conversion rate - ie. over half of the 'empty' jobs would be filled with new employees, though the Labour Marked Board emphasised that this was a very rough estimate.

\section{Table 3. Benefits and costs of paid leave arrangements - employee and employer viewpoints}

\begin{tabular}{|c|c|c|}
\hline \multicolumn{3}{|c|}{ The employee } \\
\hline & Benefits & Costs \& risks \\
\hline \multirow[t]{5}{*}{ Economic factors: } & Wage increase (E) & Income loss during leave (E/S/C) \\
\hline & Increased job-security (E) & Cost of education (E) \\
\hline & Savings on child-care (C) & \\
\hline & Personal development (E/S/C) & Risk of career stop (E/S/C) \\
\hline & Increased qualification $(E)$ & Loss of social contact (E/S/C) \\
\hline \multirow[t]{4}{*}{ Non-economic factors: } & Increased job-quality (E) & Change of environment (E) \\
\hline & More leisure-time (S/C) & \\
\hline & The employer & \\
\hline & Benefits & Costs \& Risks \\
\hline \multirow[t]{4}{*}{ Economic factors: } & Increased productivity $(\mathrm{E})$ & Training of substitute (E/S/C) \\
\hline & Increased flexibility $(\mathrm{E})$ & Wage costs of substitute \\
\hline & & Costs of education of employee (E/S) \\
\hline & & Potential loss of employees \\
\hline \multirow[t]{2}{*}{ Non-economic factors: } & Well-being of employees (E/S/C) & \\
\hline & Stronger relations with firm (E) & \\
\hline
\end{tabular}

$\mathrm{C}=$ child care leave $; \mathrm{E}=$ education leave $\mathrm{S}=$ sabbatical leave.

Source: Kongshoj Madsen 1996: 5. 
The staff and shop employees union (HK) engaged an independent research organisation - Center for Alternativ Samfundsanalyse - to survey the conversion rate for its members involved in the temporary leave schemes (Politiken Weekly, 26-10-94, p. 6). Around 16,000 of HK's members had obtained permission to take leave in the first 9 months of 1994 (just 3 percent had their leave application denied by their employer). The survey found a 75 percent conversion rate: 87 percent amongst local government employees and 65 percent amongst both state and private sector employees . On the negative side, the survey found that few long-term unemployed benefited from the high conversion rate since most new employees had been unemployed for less than 6 months.

The union rejoiced at the high conversion rate. The union believed that a contributing factor to the positive outcome had been the union's policy of pressurising for a 100 percent conversion rate for all the leave schemes. The union had also launched a 7 million DKr media campaign in favour of the leave schemes. Nevertheless, the HK union will keep a watch on the conversion rate in the future. If the conversion rate drops dramatically, the union will revert to its original demand of a 100 percent conversion rate being guaranteed through a change of the schemes' rules regarding re-employment.

Participation in the schemes has been associated with a distinct gender bias as women have used them much more than men (Arbejdsmarkedsstyrelsen 1996). Overall, women outnumber men by more than four-to-one ( 81 percent versus 19 percent) in 1995 . The child care leave accounts for the main bias since women outnumbered men by more than nine-to-one ( 92 percent versus 8 percent) while the ratio for the education leave was more than two-to-one ( 71 percent versus 29 percent) in 1995. The gender differences indicate that the traditional roles of women and men still have a huge impact on labour market responses. It is also associated with the fact that many women obtain little economic advantage out of working. According to a large-scale survey, around 25 percent of all female employees had no or little economic advantage out of working compared to the unemployment benefit (Jespersen 1996). It also appears that public sector employers have been more supportive of the leave schemes than private sector employers and this would encourage more women to participate since many more women than men work in the public sector. Likewise, the take-up amongst office and shop workers was also high and women have a strong presence in these occupations.

The disproportionable participation of women in the leave schemes cannot be applauded. Despite the changes over the last two decades, a considerable gender wage gap still exists and men are generally still framed as 'breadwinners'. There could also be longer term negative consequences of so many women taking leave. Many women have their job prospects hampered by the tenacious relationship with the labour market as women have often part-time employment and the parental leave option is predominantly used by women. This pattern could be further exacerbated by the temporary leave options. An exception may be the educational leave option since this could presumably further career prospects. Nevertheless, the withdrawal from the labour market for education reasons could still involve negative consequences. If education standards were indicative of career prospects then one would expect less gender differences since women have surpassed men in educational achievements over the last two decades in Denmark.

"Compared to other forms of adult education, it seems that educational leave is taken by the more educated employees, thus increasing rather than diminishing the unequal distribution of qualifications" (Kongshoj Madsen 1996: 15). However, it appears that the bias in favour of more educated employees have been countered somewhat because of the high participation rate of women and of unemployed people.

Finally, the income distribution has two opposing trends. On one hand, low-paid people are encouraged to participate in the schemes since they will sustain only a minor income drop (ie. there is little different between their wage and an 80 percent unemployment benefit payment). On the other hand, highly paid employees have more flexible income patterns and may therefore be able to sustain a temporary income reduction. For the highly paid, the income reduction would be modified through the effect of the progressive Danish tax system.

\section{What are the possible lessons for New Zealand?}

The outstanding feature of the leave schemes is their general popularity. Despite employer resistance and despite warnings about fiscal costs and skills shortages, these schemes gained widespread support from the population. The schemes provide further employee flexibility and choice during a period of the working life where family, career and education responsibilities combine to create considerable pressure There is no doubt that the schemes could provide a similar type of 'relief valve' for New Zealand employees. At the moment, many New Zealand employees will have difficulty in leaving partly or wholly the labour market for a period. For example, obtaining further education is often associated with considerable sacrifice and it is often just an option for the well-off sections of the workforce. Thus, the education leave scheme fits with the current focus on upskilling and re-skilling in New Zealand. It also fits with individualised action plans being developed for unemployed.

The development of the Danish leave schemes was associated with a shift both in economic policy and a more positive approach towards a 'pull strategy' in combating unemployment. Such a change would imply a change from the free market philosophy dominating public policy development in New Zealand. The possibility of such a shift can always be debated. However, the outcome of the first MMP election could indicate that new directions may be sought in public policy. Additionally, the Employment Taskforce and the subsequent policy recommendations could mean that it is possible to put more emphasis on a 'pull strategy'? For example, the trial scheme of subsidies to very long-term unemployed is the return to a very traditional employment creation approach but it could also signify a less dogmatic 
approach to combating unemployment (Rasmussen \& Schwarz 1995: 345).

The above analysis has illustrated, however, that the schemes are associated with several contentious issues. It has been problematic that certain occupations and industries have experienced skills shortages because of the widespread use of the schemes. This could easily be avoided by using some kind of quota system which limits the annual number of employees able to obtain income support for leave purposes. From a macro-economic point of view it is also preferable if the education leave scheme is introduced as opposed to the two other leave options. This may counter the gender bias since, as described above, men have been much more keen to pursue this option as opposed to the child care and sabbatical leave option. Additionally, this would also make it more straightforward to argue for suitable income support for people in low-skilled, low-paid jobs since these people are the obvious targets for an upskilling strategy. Finally, it is important that a satisfactory conversion rate is secured in order to facilitate the maximum impact on unemployment. This could be secured to some degree through the rules guiding the receipt of income support. Although a close interaction with NZ Employment Service and private recruitment organisations would also be beneficial.

It would be advantageous, therefore, to introduce the education leave scheme on a trial basis to fine-tune any application problems. This would also provide a better understanding of the associated fiscal costs and whether these costs can be justified in terms of the impact on unemployment.

\section{Future research}

There is a need for more evaluative research in the area of working time changes and leave options. The danish Social Research Institute ('Sociolforskningsinstitutet') is currently undertaking a comprehensive assessment of the Danish leave schemes. In comparison, there has been very little published research regarding the outcomes associated with the 1987 Parental Leave Act. Likewsie, little research has been done to evaluate the effects on the many people working long hours in New Zealand in the 1990s. This leaves a number of vital questions unanswered such as the long term family, health and productivity implications.

\section{Notes}

1. I have restricted the number of references to Danish sources as these will be inaccessable for most readers for language reasons.

2. Space does not allow a discussion of economic and employment relations changes in Denmark. Interested readers can consult various OECD reports, country reports about employment relations in the European Report from Incomes Data Services, London or from the European Industrial Relations Review from Industrial Relations Services, London. The reports from the Economic Council have summaries in English. There are also a number of sources available on the Internet.
3. The regional councils supported people on child care leave since it reduced kindergarten costs as demographic trends led to a shortage of kindergarten places in 1994-95.

\section{References}

Arbejdsmarkedsstyrelsen 1996 Statistiske Oplysninger om Orlovsordninger. Copenhagen: Arbejdsmarkedsstyrelsen. [customised statistics re: participation in the three temporary leave schemes].

Arbejdsministeriet 1996 Orlovsordningerne, Uge 17 - 1996. Newsletter, Copenhagen: Ministry of Labour.

Armitage, Craig \& Dunbar, Richard 1993 Labour Market Adjustment under the Employment Contracts Act. In New Zealand Journal of Industrial Relations, 18(1):94-112.

Brosnan, P. \& Walsh, P 1996 Non-standard Employment in Australia and New Zealand: Preliminary Results from a Comparative Survey. In Fells, R. \& Todd, T. (eds), Current Research in Industrial Relations, Conference Proceedings, AIRAANZ, Perth, pp. 78-87.

Callister, P 1995 Families and patterns of work: paid and unpaid parental leave in two parent families. In Morrison, P.S. (ed), Labour, employment and work in New Zealand. Proceedings of the Sixth Conference, Wellington: Victoria University of Wellington, pp. 128-135.

Department of Labour 1992-1996 Contract (various issues).

Dixon, D. 1995 Segmentation theory and the New Zealand labour market. In Morrison, P.S. (ed), Labour, employment and work in New Zealand. Proceedings of the Sixth Conference, Wellington: Victoria University of Wellington, pp. 367-372.

Gleisner, J. \& Rasmussen, E. 1995 Men in part-time work: who are they and why do they do it? Paper, Dept. of Management and Employment Relations, University of Auckland.

Harbridge, R \& Crawford, A. 1996 The Employment Contracts Act and Collective Bargaining Patterns: A Review of the 1995/96 Year. In Harbridge, R., Crawford, A. \& Keily, P. : Employment Contracts: Bargaining Trends \& Employment Law Update 1995/96. Report, Industrial Relations Centre, Victoria University of Wellington, pp. 5-52.

Harbridge, R. \& Street, M. 1995 Labour Market Adjustment and Women in the Service Industry: A Survey. New Zealand Journal of Industrial Relations, 20(1):23-34. 
Heising, K. 1996 Det aktive arbejdsmarked. Copenhagen: Frydenlund Grafisk.

Incomes Data Services 1991 European Management Guides. Terms \& Conditions of Employment. London: Incomes Data Services \& Institute of Personnel Management.

Jespersen, J. 1996 Myten om strukturarbejdslosheden. Information, 18-1-1996.

Kongshoj Madsen, P. 1996 Lifelong Learning and Paid Leave Arrangements. Paper, OECD Conference on Creativity, Innovation and Job-creation, Oslo, 11-12 January 1996.

OECD 1994 OECD Economic Surveys: Denmark 1994. Paris: OECD.

Podmore, V. 1995 Families employment and childcare arrangements. In Morrison, P.S. (ed), Labour, employment and work in New Zealand. Proceedings of the Sixth Conference, Wellington: Victoria University of Wellington, pp. 136-143.

Rasmussen, E. 1996a Workplace transformation under the Employment Contracts Act. In Fells, R. \& Todd, $T$. (eds) Current research in industrial relations, Conference Proceedings, AIRAANZ, Perth, pp.454-462.

Rasmussen, E. 1996b Chronicle. New Zealand Journal of Industrial Relations, 21(1):109-118.

Rasmussen, E. \& Schwarz, G. 1995 Chronicle. New Zealand Journal of Industrial Relations, 20(3):336347.

Savage, J. \& Cooling, D. 1996 A preliminary report on the results of a survey on the Employment Contracts Act. NZIER Working Paper 96/7, Wellington, New Zealand Institute of Economic Research.

Whatman, R. 1995 Non-standard work in New Zealand. What we know. In Morrison, P.S. (ed), Labour, employment and work in New Zealand. Proceedings of the Sixth Conference, Wellington: Victoria University of Wellington, pp. 356-366.

\section{Author}

Erling Rasmussen is a senior lecturer at the Department of Management and Employment Relations, University of Auckland, Private Bag 92019, Auckland. 